\title{
Tracing diasporic identifications in Africa's urban landscapes: evidence from Lusaka and Kampala
}

Oliver Bakewell, University of Oxford

Naluwembe Binaisa, Max Planck Institute for the Study of Religious and Ethnic Diversity, Göttingen

\section{Abstract:}

The transnational movements of Africans within the continent are seldom conceptualised as leading to diasporic identifications and relationships. In stark contrast, the migration of Africans beyond the continent, which occurs on a smaller scale, is routinely associated with diaspora formation. Drawing on fieldwork with migrants from Anglophone and Francophone West Africa and the Horn of Africa living in Lusaka and Kampala, this paper explores whether their movements gives rise to the formation of diasporic connections that sustain and reproduce identifications with the place and people of origin, over distance and through generations. The analysis illustrates how different layers of 'origin' and 'destination' factors interact to reinforce or undermine diasporic identifications in Africa's urban landscapes. The homeland where mobility is embedded in socio-economic relations that embrace transnational linkages may perpetuate connections. The conditions of urban life that impose pressures to remain outsiders may perpetuate exclusion and hinder integration.

\section{Keywords}

Diaspora formation

\section{Africa}

Migration

Belonging

Transnationalism

Reproduction of identities 


\section{Introduction}

African migration has been the subject of growing research and policy interest over the last twenty years. Much of this research has focused on international migration, framed as the movement of Africans outside the continent with far more limited research on the movement of Africans within the continent (Chikanda and Crush 2014; Bakewell 2009). The concept of diaspora has been widely adopted to understand the connections and relationships that Africans outside the continent maintain with each other and the 'homeland' as a result of these trans-continental movements (Akyeampong 2000; Alpers 2007; Jayasuriya and Pankhurst 2003; Binaisa 2011). This focus on what have been termed 'new' African diasporas (Koser 2003) is often decoupled from the earlier historical migrations and dispersals from the continent to Europe, Asia, the Caribbean and the Americas (Zeleza 2010). In the literature on both 'new' and 'old' African diasporas, the primary focus is on diaspora formations outside Africa (Bakewell 2008). ${ }^{1}$ This article takes a new direction by focusing on the movement of Africans within the continent to examine the extent to which diasporas are formed, dissolved and/or transformed. This responds to earlier scholarship that insists on the relevance of intra-African movements as a core component for the study of the emergence of Africa's diasporas (Zeleza 2005).

There is a small but growing number of studies that have explored the links between the diaspora in Europe, North America and intra-Africa populations. This includes research on Zimbabweans in Africa and Europe (Bloch 2008; McGregor 2009); the Igbo diaspora as an example of an entrepreneurial and migratory cultural group that has forged trade networks throughout West and Central Africa to the wider diaspora outside the continent (Meagher 2009); and Cameroonian and Tanzanian home town associations, highlighting the role of what the authors term the 'domestic' and 'international' diaspora to integrate analysis across the migrant communities based in Africa and the UK (Mercer, Page, and Evans 2008). While these studies include intra-African movement, they are mainly concerned with their diasporic connections with those outside the continent. Our contribution is to put the spotlight on diasporic relationships regardless of their links with external diaspora groups, following the lead of Whitehouse's recent study of the Malian population in Congo Brazzaville (Whitehouse 2012b). ${ }^{2}$

We ground our research firmly within the African continent with fieldwork carried out in two distinct urban settings, Lusaka, Zambia and Kampala, Uganda. Our aim is to focus on migrants in these cities to ask the following: do they form similar diasporic relationships? Do they maintain their Nigerian, Somali or other identifications over generations? Or is the maintenance of difference less prevalent and less important for those moving within Africa?

We have framed these questions in terms of national identity as starting point, while recognising there are various overlapping layers of identities that may be equally or more significant: perhaps looking below the nation-state to ideas of ethnicity, for example Soninke or Igbo, or more aggregate identifications, for example as West Africans. Given that these national identifiers are readily recognised (even if challenged) by all sectors of the population in both Lusaka and Kampala, they do provide an entry point for delimiting these groups that have been subject to so little research. 
Noting that the term diaspora is now discussed with so many diverse meanings that that it risks being emptied of any analytical value (Brubaker 2005), we start by clarifying how we are using the concept and why we find it helpful. In the next section we lay out the conceptual framework and the background to the case studies. In the subsequent sections, we present empirical findings around three broad headings: diasporic identifications where we show how far people identify with their 'homeland'; diasporic relationships where we examine how they sustain connections with people from the homeland; and reproducing diaspora where we look at the different strategies they adopt to pass on their identifications with the homeland through the generations. We find that there is evidence of the emergence of diasporic relationships for populations moving across Africa and highlight some of the factors that shape them. While we do not claim that these processes of diaspora formation are intrinsically different from those seen among Africans moving beyond the continent, our research brings to the fore various facets that are often downplayed in discussions about African diasporas in Europe and elsewhere.

\section{Diasporas and diasporic identifications in Africa}

Many authors have noted (Cohen 2008; Turner and Kleist 2013) how the use of the term diaspora has proliferated in recent years to take in a rather broad array of ideas and introducing many layers of meaning. It is important to recognise that diaspora serves as both a category of analysis and practice with a high volume of traffic between them (Brubaker 2013). Moreover, particularly in the post-colonial context on which we focus, there is considerable movement of the term between different arenas of practice, including the formal, institutional and popular spheres (Van Hear 2012). For example, as states seek to engage diasporas in development, they launch policies and provide resources targeted at diaspora organisations. This creates an incentive for those who can style themselves as diasporic to do so. It also creates a whole field of study as academics examine the contribution of diaspora organisations to development (Turner and Kleist 2013, 195).

In order to mark out diaspora as a category of analysis that may not match any category of practice, we focus neither on people's self-identification as diasporic, nor on their identification by others. Instead we examine their practices, in the sense of their relationships, their identifications with people and places, their networks and their related aspirations for the future for themselves and their children. In this sense, our evidence comes from observations of these identifications and relationships that we analyse as diasporic, rather than following the cues set by a simple claim to be diasporic or invocation of diaspora discourse. Hence, in our analysis we may include some respondents who reject the term diaspora, while excluding some who claim it. In short, in this article, the category of analysis, diaspora, is defined by practice, but this is not the same as the diaspora category (or categories) of practice.

This distinction is important when one considers the way the concept of diaspora has been deployed in relation to Africa in recent years, where it has been applied to an ever expanding multitude of African descent groups residing outside the continent split into subsets based on nationality (Congolese, Ugandans, Nigerians), ethnicity (Soninke, Igbos) or religious following (Muslims, Christians, native believers) (Zeleza 2005, 40). These diasporic 
identifications to homeland are likely to overlap with real, symbolic and imagined attachments found within the continent of Africa, the nation state or ethnic group (Zeleza 2010).

Moreover, they are shaped by different places, that introduce their own specific structures of social stratification that cross cut social boundaries of ethnic groups (Grillo 1974), generated by factors including socio-economic status, access to papers, cultural practices and histories, and the visibility and invisibility of 'difference'. Hence our research focuses on two distinct places to capture the complexity of diaspora formation: the cities of Lusaka, Zambia and Kampala, Uganda. By paying attention to the cleavages, embodiments and expression of poly-ethnicity within migrants' lives in these urban landscapes, we aim to avoid the homogenizing tendencies that stalk African diaspora studies (Zeleza 2005). We seek to understand how diasporic identifications form, how they are sustained and how they transform (waxing or waning) across time and space.

There are a number of studies that look at these processes among people moving to neighbouring countries or within their region - for example, the Mossi in Accra (Schildkrout 1978) or the Nubians in Uganda (Hansen 1991). If we were to focus on such cases, the findings could too easily be attributed to commonalities of language, history and religion that extend across regions. Our intention was to use case studies of Africans moving across large distances within the continent - to destinations where they might readily be identified as distant outsiders rather than neighbours - as a lens to offer a critique of debates on the formation of diasporic identifications among African populations moving outside the continent. With this in mind, the research focused on francophone West Africans from Mali and Senegal; Anglophone West Africans from Nigeria and Ghana; and people from the Horn of Africa, primarily Somalis.

\section{Studying strangers in Lusaka and Kampala}

We selected the cities of Lusaka and Kampala as field sites for this exploratory research on the grounds that, first (as discussed below) they have sufficient similarities to show up some points for comparison; and second, they were cities with which we were sufficiently familiar to undertake the research with the resources available. This research is timely for a number of reasons. With the exception of South Africa, there has been very little analysis of long distance migration within sub-Saharan Africa beyond the study of refugees or intra-regional movements. More specifically, there is very limited research into the settlement of African migrants in either Lusaka or Kampala. Given the limited empirical base, our approach for this study has been exploratory, with the aim of opening up areas for further explanation rather than reaching definitive positions.

Kampala and Lusaka share some common characteristics as capital cities of landlocked countries that were subject to British colonial rule. They have both grown enormously in the last twenty years and now have very similar size populations: 1.5 million in Kampala, 1.7 in Lusaka. ${ }^{3}$ However, their history, politics and geography makes them very different urban spaces. Kampala is on the major rail and road routes linking central Africa to the Kenyan port of Mombasa on the Indian Ocean and the strategic route north to Sudan and beyond along the Nile that starts in Uganda. The city dominates the economy of Uganda hosting 80 
per cent of the services and industrial sector (Giddings 2009). The country is set in a region that has suffered very high levels of political instability and violence over decades, and in the 1970s Uganda itself was torn apart by conflict. Since the 1980s, greater political, economic and social stability has stimulated the urban growth of Kampala and made it a destination for migrants.

Lusaka's position is in many ways more peripheral. Within Zambia, it is the largest city, but the urban centres of the Copperbelt have dominated the country's industrial output and for many years, up to the 1980s, they were the centres for urban employment (Ferguson 1999). Moreover, until the 1990s, Zambia's southern African neighbours were embroiled in wars fomented by the apartheid regime in South Africa. While Zambia itself remained largely peaceful, it paid a huge economic, political and social cost for its support for the antiapartheid struggle, receiving large numbers of refugees and having its export routes for copper through South African ports disrupted. Only in the last twenty years has Lusaka's population accelerated ahead of the Copperbelt cities.

There has been very little research into populations from other regions of Africa in the two cities, with the possible exception of Somalis in Kampala whose presence dates back to the colonial period (Iazzolino 2014). Somalis are mentioned in relation to refugee population in both cities and there are passing references to the other groups living in each city in various studies. In both countries, the number of African migrants from countries that are not neighbours is very small and their settlement has raised little comment. In Kampala, the 2002 census reported just 1,500 residents in the city with citizenship from non-neighbouring African countries. According to the 2010 census, the foreign born population of Lusaka is just 27,506, of which over half are from neighbouring countries. These census figures suggest the Somali population in the city is less than 600, the Nigerian under 200 and the other groups included in the study have less than 100 each. While such official statistics are almost certainly underestimates, they show that the groups are small. Nonetheless, the Nigerians, Somalis and Malians, who are the focus of this article, have formed sections of the population that are visible in particular economic or spatial niches in these cities making it feasible and interesting to explore how they have established these positions.

Given the small migrant populations and the lack of any sampling frame in both cities, it would have been impossible to secure a representative sample of any migrant populations. Our aim was to sample purposively to reflect diversity of background, migration history and a balanced gender split; however this proved challenging. We conducted a scoping study that set out to identify potential contacts from West Africa and the Horn of Africa in each city and to pilot guidelines for semi-structured interviews, our primary research method. The interview guide focused on migrants' personal stories, what brought them to the city; their work, leisure, place of residence; their interactions with co-nationals, the host society and other groups; and their ideas on identity for themselves and their children. Potential respondents were identified by various means. Some initial contacts arose from colleagues or business relationships with researchers. Others came by getting in touch with the leaders of the relevant community association. Others were identified simply by going to places where members of these groups were said to congregate or work. For example, it was possible to contact Somalis in Kampala in Kisenyi, an area that has come to be known as 'Little Mogadishu' where there is a very visible Somali community; in Lusaka, initial contact 
was made by visiting a particular café in a shopping mall where Somalis were known to gather for coffee. In some cases, respondents suggested others to be interviewed but there seemed to be more reluctance to make such referrals in Kampala.

In this paper we draw on interviews from Nigerian, Somali and Malian respondents as common to both sites. Formal interviews were conducted with 11 Nigerians (3 female), 9 Malians (5 female) and 7 Somalis (all male) in Lusaka; and 9 Nigerians ( 3 female), 1 Malian (male) and 6 Somalis (1 female) in Kampala. In addition, the research team had numerous informal conversations and observations in public spaces including places of worship, work, and leisure. ${ }^{4}$ While our strategy made the research feasible, we make no claim to have a representative sample. It is clearly skewed by the different entry points. In both cities, there was a class bias with our research being conducted among the relatively affluent, who had jobs or ran businesses rather than their workers or street traders. We were unable to gain the participation of the visible population of undocumented Nigerians, for example. There was also a gender and age bias. It proved difficult to secure interviews with women, particularly in Kampala. The vast majority of respondents were older migrants who had been born outside Zambia and Uganda and arrived as adults; only in Lusaka was it possible to find adult children of migrants to interview.

The length constraints of this article do not permit us to give detailed historical backgrounds for the communities under study. Instead, we provide a brief overview of our respondents' understanding of the antecedents of their communities in these two cities: the myths of origin that are being disseminated among the various groups. Economic drivers seem to dominate historical recollections. Somalis and Malians emphasised trade as a primary factor and cultural norm that embeds their movement and settlement patterns. Malians in both cities have a long-standing involvement in gem trading (Bredeloup 2007) that has diversified into other arenas such as second-hand clothing. Many are Soninke people originating from the Kayes region of Mali, who are renowned for the extent of their long distance trading networks (Whitehouse 2012b; Jónsson 2012). Their numbers ebb and flow with the state of the business but there is now a small but well established population of Malians that have been Lusaka for over twenty years. Whilst in Kampala their numbers have dwindled with the shifting of gem trade networks to other cities in the Great Lakes region.

In Lusaka, Somalis trace the growth in their community to the boom in the transport industry when the Zambian government invited them to move further south to help transport its export goods through Tanzania to avoid apartheid South Africa (Phiri 2008). In both cities, the Somali community straddles diverse immigration categories including those who hold citizenship such as Ugandan-Somalis as well as refugees reflecting continued instability and conflict.

The Nigerians in both locations referred to opportunities generated in both the private and public sectors. They first came to Lusaka in the 1980s in response to the Zambian government policy of recruiting recruit foreign specialists and boost the performance of its very weak education and health sectors. Whilst in Uganda, liberalisation of the higher education sector in the 1990s led to a boom in private universities and direct recruitment of professionals and students from Nigeria. More recently, the globalisation of markets, new trade routes and transnational connections has brought an influx of highly skilled workers 
into the financial services as well as niche sectors, such as the supply of car auto parts, which is dominated by Igbo traders (Abiola 2008).

\section{Diasporic identifications}

Diasporic identifications as a term indicates the ways that our respondents claim and enact their ties to multiple people and places. To some extent, these self-identifications reflect, but do not necessarily match, the external identifications, impressed on them by the society in which they have settled, the place of origin and the state (Brubaker and Cooper 2000, 15). Both place and the passage of time appear as important factors in people's changing negotiations of these identifications (Hall 1990) within the urban landscapes of Kampala and Lusaka leading to different outcomes.

Given that most of the respondents had been born outside Uganda or Zambia, it is hardly surprising that the majority claim some identification with the country of origin. However, it was clear that for some, this has been eroded over time as they adapted to new ways of life. In both Lusaka and Kampala, the majority of Nigerians are Igbo. However, it was only in Kampala that the sustaining connection to the homeland was expressed as an inescapable Igbo cultural obligation: 'No matter how long we have been outside the country, it is a must' Abaeze (male, age 44). This emphasis on holding on to their tradition was emphasised in the face of what Nigerians in Kampala perceived as the Ugandans' loss of their culture and adoption of Western values. From this perspective, their practices of diasporic identification reflect iterational agency (Emirbayer and Mische 1998) and a proactive tendency to protect what Ugandans have carelessly lost by policing the social boundary between groups and maintaining their diasporic identifications. In contrast, in Lusaka there was more ambivalence with some Nigerian respondents identifying more closely with Zambia. For example, Benjamin (male, age 59) said:

It's a little difficult to call myself a Nigerian because [laughs] you see I have stayed the greater part of my life in Zambia so I'm more used to the customs and traditions in Zambia than in Nigeria.

The self-identification and social obligation to uphold the culture was much more consistent among the Somali and Malian populations. In Zambia, where the vast majority of the population is Christian, people's identification with Somalia or Mali is inseparable from their religion. One Malian spoke of his main concern to raise his children as good Muslims and his Soninke culture was consistent with that aim. That said, even in the face of this apparent fundamental divide from Zambia, the passage of time could result in a growing sense of belonging. As Mohamed (male, age 49) put it:

Actually, I came to Zambia when I was very young. When I was in Mali [after spending some years in Zambia], I was not free. All my intentions were to get back to Zambia.

In addition to the passing of time, respondents' sense of inclusion in Kampala and Lusaka is another factor influencing the extent to which they sustain their strong identification with the homeland. Some claimed that they were completely accepted. For example, Benjamin, 
who now feels more Zambian than Nigerian (see above), happily reported of a meeting with Zambian colleagues, who said,

'This one [i.e. Benjamin], when he dies, even if they carry his body to Nigeria to bury, his heart is here with us in Zambia because he's one of us'.

The experience of others is rather different. While nobody spoke of violence or extreme xenophobia, many presented evidence of everyday discrimination that sustained a sense of exclusion. This takes various forms, ranging from casual encounters in the street, where Somalis are referred to disrespectfully as foreigners, to more personal objections to their promotion at work, or discrimination within institutions. A Nigerian woman facilitating a workshop for Ugandan young people to learn filmmaking skills faced complaints that she, a foreigner, should be training Ugandans. Although the participants put the heckler down, the memory still rankles and as she says serves as a reminder that she will never belong.

In Lusaka perhaps the most consistent sense of discrimination is felt among Nigerians who are negatively stereotyped as hustlers and crooks, who are not to be trusted. This view of Nigerians that prevails in Lusaka makes it much more difficult for them to establish new contacts with Zambians. There is a much more mixed picture in Kampala, where Nigerians referred to the convivial nature of Ugandans as a crucial element that attracted them to the country. While there is a criminal element, mostly among single unaccompanied men (whom one informant referred to as 'mis-drops', or migrants who had intended to settle elsewhere but had ended up in Kampala), they have not tarnished the reputation of the wider Nigerian community in the city.

Respondents also gave reports of discrimination in their encounters with various institutions in both Kampala and Lusaka. In the former, it is experienced most keenly when dealing with government departments to facilitate trade, where West African traders feel they have to pay higher taxes than other foreigners, such as Chinese and Indians. In Lusaka, members of the Somali community spoke very favourably of their dealings with government officials, who treat them reasonably as long as they have all their papers in order. They were more concerned with their encounters with the police or other officials in the streets, where they may struggle to gain a fair hearing in any disputes with Zambians.

Such experiences reinforce people's sense of being outsiders and their identification with the homeland. This is formalised by their continued status as foreign citizens. Very few had gone as far as applying for Ugandan or Zambian citizenship, even after many years of living in either country. Those who have taken citizenship refer to it in terms of pragmatism rather than reflecting their belonging to the country. This is particularly important for Somalis in Lusaka, some of whom have renounced their refugee status to secure Zambian citizenship, which brings enhanced rights to own property and a passport that is accepted for travel. In Kampala, Somalis who have refugee status are more reluctant to give it up as it is strongly associated with the dream of being selected by UNHCR for resettlement in Europe or North America. This was never mentioned among Somalis in Lusaka.

Here we have focused on people's identifications with the homeland and their current residence, giving some sense of how this is affected by both places. Of course, we cannot do justice to the complexity of people's identifications that range over many other 
configurations. In particular, it is important to emphasise that while a sense of inclusion in one place may be related to exclusion at another, it is not a zero-sum game. Moreover, there are sometimes other places at play, such as the European or North American state where someone holds citizenship.

\section{Diasporic relationships}

The extent to which individuals sustain contact with others from the homeland varies enormously. Tracing these wider networks can reveal the broader diasporic relationships that these migrant groups form, or fail to form, within Lusaka and Kampala. Different spaces in these cities provide opportunities for contact with co-nationals related to religion, livelihoods and community life. These spheres are at times inter-related and it is through those conjunctures that diasporic relationships are most visible. In both cities, personal circumstances and livelihoods are the key determinants of the extent of diasporic relationships and networks. For each of the groups, ongoing relationships between conationals in Lusaka and Kampala have been supported by the creation of formal and informal institutions as well as a variety of migrant associations.

Muslim migrant groups are very concerned to maintain their religious and cultural identity, which provides a powerful incentive to keep up strong relationships with co-nationals. In Lusaka, Malians attend one particular mosque that also has a public Islamic school (teaching the Zambian curriculum) attached to it (Phiri 2008). There is no similar primary Somali mosque for the much larger Somali community but they worship alongside other Muslim groups including Zambian Indians.

Uganda, unlike Zambia, has a local well established Muslim minority, integrated across social classes, that includes royal lineage, business leaders and highly skilled professionals. In Kampala, Somalis worship at mosques in Kisenyi, their area of high settlement, but also Malians and Somalis worship in other mosques alongside Ugandans. The mosque provides an important space for guidance and leadership on cultural issues that are seen to threaten diasporic orientation, for example, issues between parents and youth. As one Somali father notes, they depend on the mosque 'to tell children how to dress as religion and culture prescribe.'

However, these close connections reach far beyond the mosque. In Lusaka, Somali men can be seen congregating at cafés, chatting and doing business and, in the north of the city, some Somali entrepreneurs have established a couple of small business parks, where they rent offices and warehouses to fellow Somalis. In addition to these business links with other Somalis, most of them also marry within the community (see below). As a result, among the older generation, there is little socialising with Zambians, for example in weddings and funerals, and they report that their main contacts with Zambians is as employees or customers. In contrast, the Malian population, who live in a distinct area of Lusaka, appear to have many more avenues for mixing with Zambians. In particular, following the practice of Soninke in other regions of Africa (Whitehouse 2012a, 151), many of the men have married Zambian women, who convert to Islam (see below). With marriage, they acquire Zambian, and usually Christian, relatives with whom they continuously interact in family 
events and festivals. Nonetheless, most Malian born respondents said their closest friends come from the Malian community.

The diasporic linkages within each city also take institutional forms. The tradition of hometown associations is particularly strong in the Nigerian community and links them to the smaller hometown or ethnic level unit for diasporic relationships. Associations provide support to members as a vital strategy to build the strength of the diaspora and maintain commitment to the homeland. In Kampala where many migrants are far from their families, associations play a stabilising role, as Chinedu says (male, age 54):

It's not about noticing we know everything about each other here, if we see the kind of life you have that you've been profligate, womaniser, spending, we call you to order or we sanction you. If there is a case of a family problem we try to nip it in the bud, if there is some counselling needed we bring elderly people to advise.

In both cities, associations provide vital social protection particularly in times of personal duress when members are sick, or if assistance is needed for funerals or burial repatriation to the homeland.

Associations may also help build relationships with the local population, accentuating the positive contribution the 'outsiders' can make to the wider community. In Lusaka, for example, the association for Nigerians took on an ambassadorial role to reach out to Zambians supporting local charities and collecting substantial donations for two orphanages in the city. In Kampala, restaurants and bars run by Nigerians have promoted Nigerian cuisine, music and lifestyle. In these spaces of conviviality, comedy nights, music, dance and film provide opportunities for Nigerians from all walks of life to socialise with Kampala locals. Furthermore, the associations play an important role in connecting their respective communities with diplomatic missions. Again the Nigerians are the most active. The Nigerian High Commission in both Kampala and Lusaka maintains close contact with the Nigerian associations and supports national chapters of the Nigerians in Diaspora Organisation (NIDO). The associations can also provide an important point of contact for the host government. For example, the Head of Immigration in Lusaka refers to the leaders of the respective associations to deal with any matters concerning their communities. The significance of these connections needs further exploration.

There is a strong transnational dimension to these diasporic relationships, reaching back to the homeland and other parts of the world. The Somalis are clearly embedded in wider networks of Somali transnational relationships which has been well documented elsewhere (Lindley and Hammond 2014; Kleist 2008) with relatives and friends in many other African countries, Europe and North America. The long period of conflict in Somalia and the widespread scattering of people over decades has resulted in a mixed picture from the two cities. In Kampala, the Somali community maintains active links to the homeland and regional and transnational diaspora. In Lusaka more people refer to links with Somalis outside Somalia than maintaining direct contact with those living within Somalia itself. By contrast, the Malians in Lusaka maintain very close contact with their home area, particularly with the family in the village (see below); at the same time, in common with the Malians in Kampala they also have extensive networks across southern and central Africa. It 
was striking that respondents made no reference to links with the extensive Malian diaspora outside Africa.

It is clear that there are compelling material causes for maintaining these relationships, which must be considered alongside cultural explanations. In particular, for Somalis and Malians, the maintenance of relationships is an essential part of their livelihoods. The Somalis' close circles involve deep knowledge of individuals and their families going back generations, which creates a strong basis for trust and mechanism for social sanctions. They can lend money to each other to start up or expand businesses and ensure repayment. This mutual trust among co-nationals is in strong contrast to their lack of trust in financial transactions involving Zambians and Ugandans. It is this network of relationships, which helps secure reliable access to capital that enables them to maintain their advantage in business. Malians appeared to use their networks as means to identify opportunities, finding out about new mineral discoveries or changes in market conditions. The gem traders are constantly on the move around the region, following the leads given by Malians in other countries. As one Malian gem trader, Ahmed (male, age 51) put it, 'we are running after money: you hear money is this side, you go there; you hear business is that side, you go there'.

\section{Reproducing diaspora}

Diasporic relationships that are flourishing today may wither away with the passage of time and changing generations. In this section, we focus on the different strategies for sustaining identifications with the homeland among the second generations, born or raised abroad. It was possible to observe the attempts being made to reproduce diasporic identifications; it is too early to show whether they are having much success. It is only with this passage of time that one sees the emergence of a distinctly diasporic set of relationships:

The community endures as a distinct diaspora, not because its members individually remember grandma or the village, but thanks to the collective work of memory and commemoration, the performance of difference, the cultivation of ideologies of identity, and the institutionalization of practices of connection to the homeland (Tölölyan 2007, 250).

In Kampala and Lusaka, family units reflect life in the city, migration patterns as well as community expectations. The pressures for conforming to one set of cultural practices and norms can be quite complex and parental concerns make a distinction between young children and youth. On the one hand, issues of child rearing are expressed around concerns with maintenance of language, religion and food that marks communities as distinct. On the other hand, communities and individuals also respond to the new opportunities that they would not have encountered in their homeland. As one Somali woman said in Kampala, 'we have had the opportunity to study, to learn English and other languages.' The choice of marriage partner, the life stage when they migrated (some were already married when they moved), their reasons for coming and their time horizon for return are also important considerations that impact family life and strategies for reproducing diaspora.

In Lusaka, many Nigerians had married Zambians, but others travelled back home to find a Nigerian spouse with a view to finding someone who would be amenable to return in future 
years. In their discussion of the choice of marriage partners, there was little mention of upholding tradition or culture. When it came to their children, people talked of their attempts to bring them up as Nigerians but were quite relaxed in the face of the children becoming Zambian, telling jokes about how their children prefer the bland Zambian food rather than Nigerian dishes.

This is in marked contrast with Nigerians in Kampala where this debate was intricately linked to cultural identity and future return. Both Nigerians married to co-nationals and non-Nigerians feel strongly that their children will retain their Nigerian identity, however marriage to a co-national was felt to guarantee this outcome and eventual return. Peter (male, aged 36), married to a Ugandan has a baby daughter and intends to return when she is five, he explained these anxieties through the example of a long-standing Nigerian community member who had opted to stay in Kampala:

He has a daughter who is 16 with a Ugandan woman. Their daughter does not cook. Once she comes back from school she goes out to get a video or is on computer. If he asks her something she says "don't you see I am on Facebook, I am on WhatsApp" I wouldn't want to give that [behaviour] a chance; it is better for my kid to know what the world is back home.

Adaku (female, aged 34), a Nigerian married to a Ugandan has two small children and an older twelve year old daughter. This is her second time to marry outside her community as her former husband is French. She feels it is vital for her children to retain their identity as Igbo and Nigerian - and equally as African, an identification that she feels is missing in the Kampala context:

I am a proud Nigerian and I will never change my nationality. I am proud of the family I come from how I have been raised. So why should I erase that. I look at myself as an African. I believe that this is my continent and I have a right to be part of any African country, and I cannot allow anyone to intimidate me and call me a foreigner. For us Nigerians, we are raised with it [identity] we don't part from it. My daughter knows that she is an Igbo girl and where her homeland is.

The slippage between Igbo, Nigerian and African reveals the multiple registers of Adaku's diasporic orientation that she is determined to pass on to her three children. To promote this inclusive orientation her children are bilingual and versed in the knowledge of their cultural heritage: the dances, music and food as well as expected norms of behaviour.

In Lusaka, we find that Malians and Somalis are much more concerned than the Nigerians to ensure the new generation identifies with the homeland, but they adopt opposite approaches, with the Malians practicing exogamy and the Somalis endogamy. As noted above, the migration of Malians is predominantly male and while some have brought over wives from Mali, the majority have married Zambian women. These women convert to Islam and live among the Malian community in Lusaka but they introduce elements of Zambian cultures, particularly language and food, into the household and, of course, a Zambian set of relatives to the family, who are likely to expose the children to Christianity or other values incompatible with Islam. As the children get older, Malian fathers may send them 'back' to their village, where they are ostensibly looked after by the grandmother and taught the Malian (in most cases Soninke) culture. Sometimes the Zambian mothers are also 
sent 'home' to Mali and end up in the village. This can put them in a very vulnerable position, far from home and under the control of their in-laws. The age at which children are sent to Mali can vary enormously, but those who are sent during primary school age are likely to learn Soninke (and possibly French) but forget their English and Zambian languages. In some cases, only some of the children are sent, so one can find families split between Zambia and Mali, where the children struggle to speak each other's languages.

All the Somali respondents had married other Somalis and this was described as the norm in the community (see also Phiri 2008). Their children are then brought up in a Somali family in Lusaka, where they are immersed in the religion, language and culture of Somalia. At the same time these children are living in Lusaka and immersed in Zambian culture. Parents with sufficient money may send the children to private schools, but these are still following the Zambian curriculum and have very mixed student bodies, so the children may speak Nyanja, Bemba (the main Zambian languages in Lusaka) and English better than Somali. As one father put it, the children may be Zambian out of the house, but he is the father of the house, and they must be Somali there. Whether this form of Somali will be the same as that of the parents remains an open question in Lusaka.

The experience in Kampala suggests a Somali identity is likely to prevail through generations but it will be shaped by the space in which they settle. Marriage practices exhibit the same strong endogamy observed in Lusaka, however as a community Somalis come together and unite across clan and citizenship divides, as Aadan (male, 29) says:

'Even those who came in Uganda fifty years ago participate in activities organized by the Somali community. They have their businesses and got their nationality here in Uganda because they were born from here and they speak the language of this country; so by origins they are from Somalia but they are Ugandans as well. But we belong to the same community of Somalis.'

There is a tension around how to sustain diasporic identifications amongst Somali youth. Kampala is emerging as an alternative destination for Somali diaspora outside Africa who want their youth immersed in the culture, as Mukhtaar (male, age 34) said: 'they bring back their children here into Uganda, others into Somalia, to learn their culture and their language.' Meanwhile Somali youth raised in Kampala are developing alternative strategies to the older generation, seeking strength through expanding their diasporic sphere. There are several youth-led organisations that use social media extensively, compressing time and space to reach out and create an interactive diasporic space to discuss and communicate to the local and wider Somali youth diaspora. These interactions reveal alternative strategies for reproducing diaspora that focus on greater visibility and 'voice' to the priorities of Somali youth that can be quite distinct from those of the parental generation.

\section{Conclusion}

In this article we have provided a sketch of the processes of diaspora formation among the Somalis, Malian and Nigerian populations in Lusaka and Kampala. Our empirical findings show strong yet differentiated evidence of diaspora formation seen in the practices of Somalis, Malian and Nigerian populations in Lusaka and Kampala. With the exception of 
the Somalis in Kampala, we have observed the first generation of diaspora formation as the vast majority of these populations - and our respondents - were born outside Zambia or Uganda. Nonetheless, it is possible to trace out the dynamics of these migrants' lives and their changing connections with their homeland, revealing how far they are adopting diasporic identifications, relationships and strategies that perpetuate these linkages to the second generation.

Given the dearth of empirical material on African immigrant populations within Africa, our approach has been exploratory. In the absence of any basis for selecting one case study, it was necessary to cast the net wide to include a range of cases. This has provided valuable points of comparison and opened up questions for further exploration; but it comes at the expense of empirical depth. We make no claim to be exhaustive here; instead, our aim is to encourage those working on diaspora issues, especially those concerned with African diasporas, to examine more closely how diasporas are being formed, or not formed, as people settle in different parts of Africa. From this broader empirical base, it may be possible to refine and challenge the assumptions about African diasporic identities and practices beyond the continent. Therefore, in presenting the following conclusions drawn from the findings presented above, we draw attention to the implications for wider scholarship on African diasporas.

First, the comparison of these populations in two cities shows the importance of place in shaping diaspora formation. Diasporic relationships were responsive to socio-economic conditions in Lusaka and Kampala, and also to social position and cultural concerns. Moreover, for some of our respondents forms of exclusion and opportunities of inclusion had an impact on the shape and form of their diasporic relationships. Somalis settling in Kampala were drawn into the well-established Somali community institutions and mosque, strengthening their visible presence and benefiting from their acceptance in Kisenyi. In Lusaka, the Somali community was faced with carving out a niche in the life of the city from scratch.

In Lusaka social position was an important factor in the types of diasporic relationships formed by Nigerians many of whom came into the country as highly skilled migrants and joined the ranks of Lusaka's middle classes. Nonetheless, the Zambians' commonplace perception of them as crooks and shysters mean they are faced with exclusion and treated with great suspicions, creating a day-to-day wearying discrimination that prevents Nigerians from being at home. In Kampala, Nigerians remarked on conjoined opportunities for business advancement with the conviviality offered in the Kampala city landscape. Here, this process of inclusion was countered by processes of self-exclusion, as they identified important cultural differences between Nigerians and Ugandans, encouraging them to maintain the diasporic relationships to the homeland. Further research is needed to explain why these difference arise. Given the origins of the Nigerian populations in Lusaka (middle class civil servants) and Kampala (entrepreneurs and business people), one might expect prejudice to be stronger in the latter. However, it is possible that the hostile discourse on Nigerians in Lusaka is influenced by the xenophobia of its regional neighbour, South Africa (Mario Matsinhe 2011). We may also seek an explanation in difference in the prevalent attitudes to business success in the two cities. 
Whatever the explanation, we can see that diasporas look rather different in different settings. This must call into question generalised references to a diaspora which are unqualified by the place in which they are being observed. While such a point may be obvious to ethnographers, it is all too easily forgotten in research into African diasporas in Europe and North America, where the driving force of diaspora formation is often ascribed to cultural considerations derived from the homeland. Perhaps there needs to be more focus on the conditions in which people settle that shape diasporic identifications and relationships, looking more at the prevailing practices of inclusion and exclusion to be found in different cities.

This relates to the second conclusion. The examples studied here show the significance of the economic imperative underpinning people's diasporic relationships, and the enduring relevance of cultural norms particularly in the Malian and Somali communities where trade is an important driver. However, the example of Nigerians in Lusaka suggest that where people's livelihoods are derived from other employment not related diaspora links, this imperative to sustain diasporic relationships may be more subdued. Research on African diasporas in the West pays little attention to these economic incentives for diaspora formation. There is a body of research on trade diasporas and diaspora entrepreneurship (for example, see McCabe, Harlaftis, and Minoglou 2005), but when it comes to studies on Africans in Europe and North America, the primary focus is on how diaspora businesses generate remittances or investments in the place of origin (Plaza and Ratha 2011). The diaspora is taken as a given and the economic motivations for its formation remain underexplored.

Finally, while these structural conditions derived from the place and society in which people settle and their economic circumstances play a critical role in shaping diaspora formation, it is clear that the formation of diasporic identifications and relationships and the strategies adopted to reproduce them through the generations are a reflection of people's agency. This was perhaps most visible among the Nigerians, where there was considerable variation in the extent of people's diasporic practices. Given that the scope of our research was limited largely to migrants in relatively secure positions in each city, further research that includes those in more precarious positions and the second generation will likely reveal a more complex mix of diasporic identifications and relationships. In these African contexts, it remains a critical question whether different people will seek to create and sustain a diasporic identity. In contrast, in much debate about Africans moving beyond the continent, this question is all too rarely asked: instead, those who come from the same place of origin are assumed to come together in the diaspora by definition.

We make no claim that this is an exhaustive account of these changing relationships with the homeland and its people. There are many facets which could be explored further such as the political engagement of these groups and their relationship to the state of origin. Moreover, we are very aware that the future evolution of these emerging diasporas remains very uncertain. Will they blossom and become entrenched as visible minorities; or dissolve into disconnected family stories of origins 'abroad' but no substantive link with that place of origin? This can only be shown through future research, for which we have started to lay down an empirical baseline. 
Our tentative conclusions do not suggest that there is necessarily a clear distinction between the processes of diaspora formation among Africans settling in other regions of the continent and those who are found elsewhere in the world. In this article, we have shown that opening up this new site of empirical enquiry does highlight some of the gaps in the growing body of research into different African diasporas, especially in the Global North. However, further enquiry may reveal more substantive distinctions, such as the particular role of ethnolinguistic, religious, national or even regional identities for those who move within Africa. For those moving beyond the continent, it is their African origins that may mark them out and generate a sense of identification with the wider African Diaspora. How these different layers of diasporic identifications intersect and affect each other is a question that lies beyond the scope of this research. Further comparisons between diasporas within and without Africa may be one useful avenue for exploring this in more detail. This will make it possible to see how far the processes of diaspora formation and dissolution mirror those observed among people of African origins living outside the continent; or reveal the distinctive quality of African diasporas within Africa.

\section{Endnotes}

${ }^{1}$ We should emphasise that here we are focusing on the new African diasporas; this echoes the literature on 'new' diasporas originating from other continents (Van Hear 1998; Appadurai 1996).

2 There is also extensive literature on non-African diasporas within Africa; that is those, such as the Lebanese or Indians whose diasporic homeland lies outside the continent (Akyeampong 2006; Ghai and Ghai 1971). However, for this article our focus is on those with 'homelands' in Africa.

${ }^{3}$ These and subsequent population figures are taken from the census reports published by the Ugandan Bureau of Statistics (www.ubos.org) and the Zambia Central Statistics Office (www.zamstats.gov.zm). The provisional results for the 2014 Uganda Census do not yet give figures for the foreign-born population [accessed August 2015] so we have had to use data from the 2002 census where necessary.

${ }^{4}$ In Kampala, for example although much time was spent observing and conversing with Malian traders in their work space, only one formal in-depth interview was obtained from the head of the community, who has resided in Kampala since 1974.

\section{Acknowledgements}

We are indebted to Wilma Nchito, Lecturer in the Department of Geography at the University of Zambia, for her work in identifying respondents and conducting interviews in Lusaka that have made an important contribution to this article. We acknowledge the financial support of the Leverhulme Trust, which funded the Oxford Diasporas Programme, of which this project is part and we are grateful to our colleagues in the programme for their comments and feedback as these ideas have been developed. We are also grateful to the four anonymous referees who gave helpful comments to improve the final article.

\section{References}

Abiola, Boladale. 2008. "Knowledge, Technology and Growth: The Case Study of Nnewi Auto Parts Cluster in Nigeria." In Knowledge, Technology, and Cluster-based Growth in Africa, edited by Douglas Zhihua Zeng, 53-64. Washington DC: World Bank. 
Akyeampong, Emmanuel K. 2006. "Race, identity and citizenship in black Africa: The case of the Lebanese in Ghana." Africa 76 (3): 297-323.

Akyeampong, Emmanuel K. 2000. "Africans in the Diaspora: The Diaspora and Africa." African Affairs (395): 183-215.

Alpers, Edward A. 2007. African Diasporas: A Global Perspective. London: Routledge.

Appadurai, Arjun. 1996. Modernity at Large: Cultural Dimensions of Globalization. Minneapolis: University of Minnesota Press.

Bakewell, Oliver. 2008. "In Search of the Diasporas within Africa." African Diaspora 1 (1): 527.

Bakewell, Oliver. 2009. "South-South Migration and Human Development: Reflections on African Experiences." Human Development Research Papers 2009/07. New York: United Nations Development Programme.

Binaisa, Naluwembe. 2011. "Negotiating 'Belonging' to the Ancestral 'Homeland': Ugandan Refugee Descendents 'Return'." Mobilities 6 (4): 519-34.

Bloch, Alice. 2008. "Zimbabweans in Britain: Transnational Activities and Capabilities." Journal of Ethnic and Migration Studies 34 (2): 287-305.

Bredeloup, Sylvie. 2007. La Diams'pora du fleuve Sénégal: Sociologie des migrations africaines. Toulouse: Presses universitaires du Mirail.

Brubaker, Rogers. 2005. "The 'Diaspora' Diaspora." Ethnic and Racial Studies 28 (1): 1-19.

Brubaker, Rogers. 2013. "Categories of analysis and categories of practice: a note on the study of Muslims in European countries of immigration." Ethnic and Racial Studies 36 (1): $1-8$.

Brubaker, Rogers, and Frederick Cooper. 2000. "Beyond 'identity'." Theory and Society 29 (1): $1-47$.

Chikanda, Abel, and Jonathan Crush. 2014. "Diasporas of the South." In A New Perspective on Human Mobility in the South, edited by Rudolf Anich, Jonathan Crush, Susanne Melde and John O. Oucho, 65-8. Dordrecht: Springer.

Cohen, Robin. 2008. Global diasporas: an introduction. London: UCL Press.

Emirbayer, Mustafa, and Ann Mische. 1998. "What Is Agency?" American Journal of Sociology 103 (4): 962-1023.

Ferguson, James. 1999. Expectations of Modernity: Myths and Meaning of Urban Life on the Zambian Copperbelt. Berkeley: University of California Press.

Ghai, Yash P., and Dharam P. Ghai. 1971. The Asian minorities of East and Central Africa (up to 1971). London: Minority Rights Group. 
Giddings, Stephen W. 2009. "The Land Market in Kampala, Uganda and its Effect on Settlement Patterns." In, 33. Washington DC: International Housing Coalition.

Grillo, Ralph. 1974. "Ethnic Identity and Social Stratification on a Kampala Housing Estate." In Urban Ethnicity, edited by Abner Cohen, 159-85. London: Tavistock.

Hall, Stuart. 1990. "Cultural Identity and Diaspora." In Identity: community, culture, difference, edited by Jonathan Rutherford, 222-37. London: Lawrence \& Wishart.

Hansen, Holger Bernt. 1991. "Pre-Colonial Immigrants and Colonial Servants. The Nubians in Uganda Revisited." African Affairs 90 (361): 559-80.

Iazzolino, Gianluca. 2014. "A Safe Haven for Somalis in Uganda?" Rift Valley Institute Briefing Paper August 2014. Nairobi: Rift Valley Institute.

Jayasuriya, Shihan de Silva, and Richard Pankhurst. 2003. The African diaspora in the Indian Ocean. Trenton, NJ: Africa World Press.

Jónsson, Gunvor. 2012. "Migration, identity and immobility in a Malian Soninke village." In The Global Horizon: Expectations of Migration in Africa and the Middle East, edited by Knut Graw and Samuli Schielke, 105-20. Leuven: Leuven University Press.

Kleist, Nauja. 2008. "In the Name of Diaspora: Between Struggles for Recognition and Political Aspirations." Journal of Ethnic and Migration Studies 34 (7): 1127 - 43.

Koser, Khalid, ed. 2003. New African Diasporas. London: Routledge.

Lindley, Anna, and Laura Hammond. 2014. "Histories and contemporary challenges of crisis and mobility in Somalia." In Crisis and Migration: critical perspectives, edited by Anna Lindley, 46-72. Abingdon, Oxon; New York: Routledge.

Mario Matsinhe, David. 2011. "Africa's Fear of Itself: the ideology of Makwerekwere in South Africa." Third World Quarterly 32 (2): 295-313.

McCabe, Ina Baghdiantz, Gelina Harlaftis, and Iōanna Pepelasis Minoglou, eds. 2005. Diaspora entrepreneurial networks: four centuries of history. Oxford: Berg.

McGregor, Joann. 2009. "Associational links with home among Zimbabweans in the UK: reflections on long-distance nationalisms." Global Networks 9 (2): 185-208.

Meagher, Kate. 2009. "The Informalization of Belonging: Igbo Informal Enterprise and National Cohesion from Below." Africa Development 34 (1): 31-46.

Mercer, Claire, Ben Page, and Martin Evans. 2008. Development and the African diaspora: place and the politics of home. London: Zed Books.

Phiri, Felix J. 2008. Muslim Associations and the Resurgence of Islam in Zambia. Lusaka: FENZA and Lembani Trust. 
Plaza, Sonia, and Dilip Ratha, eds. 2011. Diaspora for Development in Africa. Washington DC: World Bank.

Schildkrout, Enid. 1978. People of the Zongo: the transformation of ethnic identities in Ghana. Cambridge: Cambridge University Press.

Tölölyan, Khachig. 2007. "The Contemporary Discourse of Diaspora Studies." Comparative Studies of South Asia, Africa and the Middle East 27 (3): 647-55.

Turner, Simon, and Nauja Kleist. 2013. "Introduction: Agents of Change? Staging and Governing Diasporas and the African State." African Studies 72 (2): 192-206.

Van Hear, Nicholas. 1998. New diasporas: the mass exodus, dispersal and regrouping of migrant communities. London: UCL Press.

Van Hear, Nicholas. 2012. "Forcing the Issue: Migration Crises and the Uneasy Dialogue between Refugee Research and Policy." Journal of Refugee Studies 25(1): 2-24.

Whitehouse, Bruce. 2012a. "Centripetal Forces: Reconciling Cosmopolitan Lives and Local Loyalty in a Malian Transnational Social Field." In West African migrations: transnational and global pathways in a new century, edited by Mojubaolu Olufunke Okome and Olufemi Vaughan, 145-66. New York: Palgrave Macmillan.

Whitehouse, Bruce. 2012b. Migrants and strangers in an African city: exile, dignity, belonging Bloomington: Indiana University Press.

Zeleza, Paul Tiyambe. 2005. "Rewriting the African diaspora: Beyond the black Atlantic." African Affairs 104 (414): 35-68.

Zeleza, Paul Tiyambe. 2010. "African Diasporas: Toward a Global History." African Studies Review 53 (1): 1-19.

OLIVER BAKEWELL is Director of the International Migration Institute and Associate Professor at the Department of International Development, University of Oxford, OX1 3TB, UK. Email: oliver.bakewell@qeh.ox.ac.uk

NALUWEMBE BINAISA is Research Fellow at the Max Planck Institute for the Study of Religious and Ethnic Diversity, Hermann-Föge-Weg 11, D-37073 Göttingen, Germany. Email: Binaisa@mmg.mpg.de 